https://helda.helsinki.fi

\title{
Linking and copyright : a problem solvable by functional-technical concepts?
}

\section{Pihlajarinne, Taina Elisa}

\section{Edward Elgar}

2019-01-25

Pihlajarinne, T E 2019 , Linking and copyright : a problem solvable by functional-technical concepts? in T Pihlajarinne , J Vesala \& O Honkkila (eds), Online Distribution of Content in pÿthe EU . , 3 , Edward Elgar, Cheltenham, UK , pp. 2539 . https://doi.org/10.4337/9781788119900.00009

http://hdl.handle.net/10138/309279

https://doi.org/10.4337/9781788119900.00009

unspecified

acceptedVersion

Downloaded from Helda, University of Helsinki institutional repository.

This is an electronic reprint of the original article.

This reprint may differ from the original in pagination and typographic detail.

Please cite the original version. 
This is a draft chapter. The final version is available in Online Distribution of Content in the EU edited by T. Pihlajarinne, J. Vesala, \& O. Honkkila, published in 2019, Edward Elgar Publishing Ltd http://dx.doi.org/10.4337/9781788119900.00009

The material cannot be used for any other purpose without further permission of the publisher, and is for private use only. 
Linking and copyright - a problem solvable by functional-technical concepts?

Taina Pihlajarinne*

\section{Introduction}

Linking as such is nothing new in copyright discussion - a discussion that started in the early 1990s. However, the Internet, its business models and linking activities as part of those models has undergone thorough changes. Indeed, as opposed to early discussion that concerned linking in its simple form in an undeveloped Internet, nowadays it is questionable whether linking can be discussed as a single, discrete phenomenon. Moreover, the role of a link has changed: while its immediate function is to deliver information on the location of a particular entity's web address, in a broader perspective the claim might be made that linking is also in certain cases used as a tool for de facto content distribution.

In this connection, it seems that the CJEU's endeavour to create clear and predictable rules on linking, which as such is understandable, has unfortunately led to a failure to differentiate various linking situations. This is because differentiation might have contributed to the attempt to resolve some of the problems on linking-related business models with a solution of a very straightforward nature, that is to say, the proposed new related right.

Press publishers have accused news aggregation services of free-riding on publisher-produced news content. As publishers did not obtain the response they wished for through CJEU practice on linking - they could not defeat this long-term battle by interpretations of linking as an act of communication to the public - they instead managed to convince the European Commission through arguments that news aggregation services threaten the functioning and vitality of the press sector. The Commission has proposed that press publishers be granted a related right under Article 11 of the proposal for a Directive on copyright in the Digital Single Market (DSM). While the proposal does not directly affect the legal status of linking ${ }^{1}$, it is clearly directed at the activities of news aggregation services. However, the proposal incorporates

\footnotetext{
*Professor, University of Helsinki Faculty of Law, Finland.

${ }^{1}$ According to art 11, the exclusive right would cover reproduction and making available to the public of press publications to the extent that digital uses are concerned. Rec 33 of the proposal for a Directive on copyright in the Digital Single Market states that the new 'protection does not extend to acts of hyperlinking which do not constitute communication to the public'. Commission, 'Proposal for a Directive on copyright in the Digital Single Market' COM(2016) 593 final.
} 
many serious problems: the proposed right could unnecessarily obstruct other legitimate interests such as freedom of expression as it does not take into consideration the divergence of online services. In fact, introducing a new related right would only further complicate and fragment EU copyright law. ${ }^{2}$ Could this kind of one-eyed policymaking be avoided if more nuanced solutions were adopted in considering linking ${ }^{3}$ - by distinguishing between linking for loyal and disloyal purposes: for instance, paying more attention to commercial or uncommercial, systematic or occasional nature of linking, as well as whose acts are decisive in selection of linked material, and whether links are genuinely used to imply the location of certain material, or as tools for de facto distributing the works of others? At the same time, evaluation of linking should be based on flexible guidelines, since future AI-based digitality will challenge the feasibility of any standpoints that are currently relevant.

We cannot know for sure. While it is possible that the answer is affirmative, another option is that there is nothing that could have hindered rightholders from creating the political pressure that led to the Commission proposal. However, in this Chapter I will assess what alternative solutions might be available.

\section{Diversity of linking and legitimate interests}

As a remarkable challenge for legal assessment, linking situations do not form any kind of homogenous group in terms of assessing their functions and impacts. Commercial linking includes a wide scope of situations with different impacts and divergent interests, as indeed does linking by private persons. These need to be recognised and the interests evaluated further.

\footnotetext{
${ }^{2}$ It is also doubtful whether the proposal can address concerns about the weak bargaining position of news publishers, as similar national rights have proved failures. See more on the problems relating to the proposal, for instance, C Geiger, O. Bulayenko and G. Frosio, 'The introduction of a neighbouring right for press publishers at EU level: the unneeded (and unwanted) reform' (2017), 39 (4) EIPR 202, 208-209; T. Pihlajarinne and J. Vesala, 'Proposed right of press publishers: a workable solution?' 1 (2018) Journal of Intellectual Property and Practice 220, 220-228.

${ }^{3}$ As to details, many aspects of the CJEU's linking practice have provoked criticism. For instance, Mezei expected that the CJEU would have sought an internal rebalance in its GS-media and Filmspeler cases. This assessment would have weighed copyright concepts and social norms against each other more carefully. Mezei suggested introduction of new concepts such as 'innocent dissemination'. In this way, the need for time-consuming legislative procedures could have been avoided. P Mezei, 'Enter the matrix: the effects of CJEU case law on linking and streaming technologies' 10 (2016) Journal of Intellectual Property Law and Practice 778, 794. Leistner has pointed out that the CJEU's practice on linking to legal sources has gone too far: for instance, it is problematic that the CJEU also allows embedding and therefore individual content can be placed almost freely in a new context. On the other hand, Leistner states that the presumption of knowledge in practice of linking to illegal sources causes a danger that courts will not limit the presumption in a realistic way. In addition, changes which are not easy to identify might occur in terms of the legal status of linked material. A consequence might be a continuous monitoring duty. M. Leistner, 'Closing the book on the hyperlinks: brief outline of the CJEU's case law and proposal for European legislative reform’, EIPR 2017, 39(6), 327, 329-332.
} 
News aggregation is one example of this diversity. It is a highly contradictory issue whether news aggregation services, by serving as substitutes, might negatively affect right holders' advertizing incomes and disadvantage them on pricing advertizing space - because the aggregator does not have to invest in content production - or whether aggregation solely benefits online news producers. ${ }^{4}$ However, it is probable that great diversity exists as to effect between the types of news aggregation services. For instance, those news aggregation services that include only collections of simple hyperlinks are inclined to increase the number of visitors to the news publisher's site since the only way for a user to read more than only the headline of a news article is to click the link and to go to the publisher's site. In that case, news aggregation services are probably beneficial purely for press publishers. In contrast, services in which a substantial part of news items are available directly on the news aggregation providers' site might have a significant effect on rightholders' incomes on the basis of operating as a substitute for news publishers. In that case, the news aggregation service provider might collect advertizing income at the expense of the press publisher's potential revenues. This might mean free-riding, at least to some extent. However, one guideline could be that only clear cases of systematic free-riding should be noteworthy, since free-riding as such should be tolerated to some extent in society. ${ }^{5}$ Therefore, only free-riding that has a disturbing or damaging effect on the fundamental goals of the IPR system, such as maintaining incentives for creative work, should be recognised in any assessment.

In addition, while some aggregation services are only collections of simple hyperlinks, others may use linking as a factual tool for content distribution. An extreme case here might be services forming news collections that look like individual, virtual magazines. Here, new personal products are generated by utilizing copyright material. Moreover, evaluation is not made any easier if we factor in the variable that, besides the type of news aggregation service,

\footnotetext{
${ }^{4}$ On this discussion, see, eg, E Rosati 'Neighbouring Rights for Publishers: Are National and (Possible) EU Initiatives Lawful?' (5) 2016 International Review of Intellectual Property and Competition Law 569, 569; M Stanganelli, 'Spreading the News Online: A Fine Balance of Copyright and Freedom of Expression in News Aggregation' 34(11) 2012 EIPR 745, 746-747; F. Mukaddam 'Online News Aggregation Services: The Dispute' 15(2) 2013 E-Commerce Law \& Policy 3, 3-5.

${ }^{5} \mathrm{Eg}$, Cooper Dreyfuss states that the intellectual property system is not aimed at preventing free-riding. Freeriding is a part of everything: in principle, it is free-riding to learn from a colleague's teaching techniques or a merchant who benefits from a rival's actions that raise interest in a product category. R. Cooper Dreyfuss 'Reconciling trademark rights and expressive values: how to stop worrying and learn to love ambiguity'. In (eds) G Dinwoodie, M Janis Trademark Law and Theory. A Handbook of Contemporary Research. Edward Elgar Publishing 2008 261, 285.
} 
the type of news publisher might also result in crucial differences. Small and lesser-known publishers might find aggregation more beneficial than bigger ones, since aggregation makes their websites far more visible for users.

A remarkable diversity is present in terms of the effects of freedom of expression when assessing linking in various situations. Very often the ultimate purpose of linking is purely to deliver information on the location of a particular entity's web address. Additionally, linking for business-oriented purposes covers a broad range of situations. For instance, in some services, content consists solely of links to others' copyrighted material, while some services include other material as well. Displaying links to copyrighted works in social media services might, for instance, awaken political discussion that resorts to the core of freedom of speech due to its essential importance to democracy.

It is of utmost importance for the free flow of information that services that are equivalents to search engines are not restricted without due reason. ${ }^{6}$ Therefore, when evaluating reading and aggregation services we should also assess to what extent these services are genuine tools for searching and processing information or whether they are instead comparable to distributing others' copyright-protected work, and hence content production in its broadest sense? In addition, without some of these services, information would be impossible to find, whereas some services only make control of material easier for users.

These differences make it hard to find any consistent and unambiguous basis for assessing the impacts of linking. Due to divergent situations and interests, consideration of linking in copyright cannot be based on simple and straightforward rules. Instead, a case-sensitive means of weighing and balancing those interests is needed.

III. Problems in the nature of key copyright concepts

Historical developments of basic concepts

The basic concepts in copyright are the outcome of historical development. In this context, Johannes Gutenberg's introduction of the printing press in Europe in 1439 is a crucial

\footnotetext{
${ }^{6}$ On various Internet platforms and their relationship with freedom of speech, see BJ Jütte 'The Beginning of a (Happy?) Relationship: Copyright and Freedom of Expression in Europe' (1) 2016 EIPR 11, 11-22 and A Murray Information Technology Law Oxford University Press 2010 110-124. On the freedom of speech argument in the context of news aggregation services, see Stanganelli (n 4), 748-750.
} 
benchmark. The Renaissance period was characterized by an increasing number and wide variety of intellectual creations, which created an attitude of ownership of these creations and a gradual need for copyright protection. Growing printing activity in the 15th century was associated with Venice being granted the first printing privileges and thereafter the expansion of printing privileges elsewhere in Europe during the 16th century. This meant the possibility to obtain permission for a printer's exclusive monopoly to print a particular text in order to secure the printer's investment, which in turn was extensive because of the expense of printing. ${ }^{7}$ In England, the first law to create a modern-type copyright, the Statute of Anne in 1710 , recognized the right for authors to print books but not for printers. ${ }^{8}$ The area of exclusivity under the Statute of Anne covered printing, re-printing and importing books. ${ }^{9}$ When considering the scope of exclusivity, the act was mainly focused on printing of books, that is to say, one particular form of reproduction. However, the act recognised importing books as a relevant act - which is today considered as a particular method of distributing copies of works to the public.

After that, a similar development took place elsewhere in Europe and the United States. Gradual development and expansion made these rights more extensive. Finally, pressure for enhanced international copyright protection was the reason for introducing the first drafts of the Berne Convention in $1886 .{ }^{10}$ In many countries, exclusive rights were centred around the right of reproduction, though also including provisions on different forms of making a work available to the public. Notwithstanding, the original version of the Convention did not include explicit provisions on general exclusive rights of reproduction or the right to make available. However, the original Convention contained several references to reproduction. ${ }^{11}$ A general

\footnotetext{
${ }^{7}$ Printing required investment in very expensive specialist equipment. This new business model of publishing, in other words, producing books for sale, involved risks. See I Gadd, 'The Stationers' Company in England before 1710'. In (eds) I Alexander and H T Gomez-Arost, Research Handbook on the History of Copyright Law. Edward Elgar Publishing 2016, pp. 81, 82-83.

${ }^{8}$ However, it is unclear whether the ultimate purpose of the Statute of Anne was to benefit authors, booksellers or the public in general. See more, B Lauriat, 'Copyright History in the Advocate's Arsenal'. In Alexander \& Gomez-Arostegui (n 7), 7, 22-24.

${ }^{9}$ See more I Alexander 'Determining Infringement in the eighteenth and nineteenth centuries in Britain: A ticklish job'. In Alexander \& Gomez-Arostegui (n 7) 174, 175-177.

${ }^{10}$ See, eg, N Koutras 'History of Copyright, Growth and Conceptual Analysis: Copyright Protection and the Emergence of Open Access' 2:2016 Intellectual Property Quarterly 2: 135, 138-147; F Makeen Copyright in a Global Information Society. The Scope of Copyright Protection Under International, US, UK and French Law. Kluwer Law International 2000, 1-10.

${ }^{11} \mathrm{Eg}$, the adaptation right included the right of reproduction. According to art 10, 'The following shall be specially included amongst the illicit reproductions to which the present Convention applies: unauthorized indirect appropriations of a literary or artistic work, of various kinds, such as adaptations, musical arrangements, etc., when they are only the reproduction of a particular work, in the same form, or in another form, without essential alterations, additions, or abridgments, so as not to present the character of a new original work.' The adaptation
} 
exclusive right of reproduction was adopted in the Berne Convention ('in any manner or form', article 9) as late as 1967 (Stockholm Act). Historically, the right to distribute copies of a work emanated from gradual development of being separated from the right of reproduction and recognized as an individual exclusive right in Member States' copyright acts. The general right of distribution was adopted in the WIPO copyright treaty in 1996 (Article 6). ${ }^{12}$

Exclusive rights, and concepts as their building blocks, have been under continuous reevaluation and expansion. In the early stages of digitalisation, in the 1990s, the general focus of discussion on international copyright conventions seems to have been on ascertaining that exclusivity based on traditional copyright concepts also covers digital acts. ${ }^{13}$ For instance, due to digital change, in the WIPO Copyright Treaty the exclusive right of 'making available' was extended to digital transmissions on the Internet, since the traditional way of defining communication to the public adopted in the Berne Convention does not encompass such means of utilizing works. ${ }^{14}$ However, these developments have not changed the core nature of concepts, which still have their roots in the business model of printing and selling books.

Essentially, economic rights in modern copyright consist of two basic pillars: the right of reproduction and an exclusive right to make works available to the public via several alternative means, for instance, by public performance, distribution of copies, or communication to the public. Of these two fundamental concepts, the right of reproduction is perhaps the least suitable for the digital environment as new methods and practices of reproduction fundamentally challenge the general doctrines of copyright. ${ }^{15}$ Making available to the public and its sub-concepts such as communication to the public - might be somewhat easier to adapt

right tacitly included the right to reproduction. Similarly A Dixon, and M Hansen 'The Berne Convention enters the digital age', 18(11) EIPR 604, 604. There was also a provision concerning an exception to a reproduction right in article 7 (Articles from newspapers or periodicals could be reproduced in the original or in translation in the other countries of the Union, unless explicitly forbidden by authors or publishers).

12 On historical development, see Dixon and Hansen (n 11), 609-610.

${ }^{13}$ For instance, one aim of the development that subsequently led to the WIPO Copyright Treaty (a proposal for a protocol of the Berne Convention in 1996) was to reaffirm that the reproduction right is not limited to tangible or permanent copies of a work, by stating that both permanent and temporary acts of reproduction constitute an act of reproduction. See Dixon and Hansen (n 11), 608-609. The Agreed Statements concerning the WIPO Copyright Treaty stated that 'the reproduction right, as set out in Article 9 of the Berne Convention, and the exceptions permitted thereunder, fully apply in the digital environment, in particular to the use of works in digital form. It is understood that the storage of a protected work in digital form in an electronic medium constitutes a reproduction within the meaning of Article 9 of the Berne Convention.'

${ }^{14}$ Eg, H Saito, 'Significance of the Making Available Right'. In Karnell et al (eds) Liber Amicorum Jan Rosén. eddy.se 2016, 709, 710-716; Makeen (n 10), 289-294 and Dixon \& Hansen (n 11), 610.

15 See more on problems relating to the concept of reproduction and on alternative solutions T Pihlajarinne: 'Should we bury the concept of reproduction - towards principle-based assessment in copyright law?' 8 (2017) International Review of Intellectual Property and Competition law, 953, 953-976. 
to the new technological and economic environment. One indication of such adaptability might be the CJEU's efforts to introduce and develop the notion of a 'new public'. ${ }^{16}$ However, this ease emerges only in comparison with the adaptability - or in fact, the inadaptability - of the concept of reproduction. Like the notion of reproduction, 'making available' is functionaltechnical by its very essence. The difference is that making available to the public leaves the door slightly more open for interpretation than reproduction. This is because the notion of 'public' is vaguer and more abstract than 'reproduction', which directly refers to copying of any kind. Notwithstanding, making available to the public - or, in particular, communication to the public - also involves evaluation through technical-functional lenses rather than consideration of legitimate interests. This is also demonstrated by the very detailed formulation of 'communication to the public' under the InfoSoc Directive (article 3 (1)) and the WIPO Copyright treaty (article 8): 'by wire or wireless means, including the making available to the public of their works in such a way that members of the public may access them from a place and at a time individually chosen by them.'

The ultimate problem is the same as in reproduction: the nature of the concept of communication to the public inevitably leads the interpreter to assess certain actions per se. Actions as such do not necessarily indicate what kind of effect they have on relevant interests. A certain level of vagueness and openness to interpretation is needed to achieve a capability for genuine adaptation. A second important factor is that, while surrounding reality is faced with an accelerated dematerialization process, the concept of reproduction is inevitably tied to fixation. This contradiction underlies the problematic nature of the concept of reproduction in the digital age - whereas making available to the public as such is more neutral because the 'public' as a concept, for instance, is more technology-neutral. Therefore, in comparison to reproduction, communication to the public is a concept that leaves slightly more space for creating new doctrines and weighing and balancing interests. The CJEU's preliminary rulings, which will be discussed next, demonstrate that difference.

IV. Two lines of cases - is it so simple?

\footnotetext{
16 The CJEU has concluded that the work must be directed at a new public, that is to say, at a public that was not taken into account by the copyright holders when they authorised the initial communication to the public (eg, Svensson, Sjögren, Sahlman, Gadd v. Retriever Sverige AB, C-466/12; Sociedad General de Autores y Editores de España (SGAE) v. Rafael Hoteles SA, C-306/05 and Organismos Sillogikis Diakhirisis Dimiourgon Theatrikon kai Optikoakoustikon Ergon v. Divani Acropolis Hotel and Tourism AE, C-136/09).
} 
During the past few years, the CJEU has issued several preliminary rulings on linking as an act of communication to the public. The first case that could be described as a landmark case was Svensson C-466/12, ${ }^{17}$ where the CJEU held that a provision on a website of clickable links to works freely available ${ }^{18}$ on another website does not constitute an act of communication to the public, since there is no new public. ${ }^{19}$ In the next case, BestWater $C-348 / 13,{ }^{20}$ the Court concluded that creating links to copyrighted work freely available on the Internet using a framing technique cannot be classified as communication to the public if the work is not transmitted to a new public. In both cases, the linked material was submitted as being freely available on the Internet with the rightholder's permission.

Subsequently, two more cases were decided, GS Media, C-160/15, ${ }^{21}$ and Filmspeler, C$527 / 15 .^{22}$ These form the second part of the CJEU's linking saga so far. In GS Media, linking to material freely available without the rightholders' consent was considered as an act of communication to the public. The court concluded that an assessment must be made as to whether links are provided without pursuit of financial gain by a person who did not know or could not reasonably have known of the illegal nature of the publication of those works on that other website or whether, on the contrary, links are provided for that purpose, a situation in which that knowledge must be presumed. In Filmspeler, the court held that the sale of a multimedia player for which pre-installed add-ons contained hyperlinks to websites freely accessible to the public, on which copyright-protected works were made available to the public without the consent of the right holders, amounted to communication to the public. The court referred to GS Media and stated that in Filmspeler it was evident that there was full knowledge of the add-ons containing hyperlinks that gave access to works published illegally on the Internet. In addition, the multimedia player was supplied with a view to profit, the price for the multimedia player being paid in particular to obtain direct access to protected works available on streaming websites without the consent of the copyright holders.

\footnotetext{
${ }^{17}$ Svensson et al $v$. Retriever Sverige $A B, \mathrm{C}-466 / 12$.

${ }^{18}$ However, when a link circumvents restrictions on public access to the work that are aimed at restricting access only to subscribers, eg, there is a new public and linking constitutes an act of communication to a new public (see Svensson, para 31).

${ }^{19}$ For more about the case, see, eg, Arezzo, Emanuela 'Hyperlinks and making available right in the European Union - what future for the Internet after Svensson?' 5:2014 International Review of Intellectual Property and Competition Law, 524, 524-555.

${ }^{20}$ BestWater International GmbH v. Michael Mebes and Stefan Potsch, C-348/13

${ }^{21}$ GS Media BVv. Sanoma Media Netherlands BV et al., C-160/15

22 Stichting Brein v. Jack Frederik Wullems (Filmspeler), C-527/15
} 
There is indeed a clear division between the two lines of cases. Svensson and Bestwater are 'cold' cases in which the CJEU did not open the various interests relating to the range of linking situations, such as freedom of speech and economic arguments asserted in those cases. This is surprising since Svensson, in particular, is a case with a strong basis in freedom of expression. ${ }^{23}$ However, in GS Media and Filmspeler, the economic interests are at some level taken into account, even though only indirectly, as part of the assessment of awareness of the illegal nature of material. Of course, a substantive division between these two sets of cases is natural because of the crucial division between whether - or not - linked material was on a site with the rightholder's permission.

In cases of legal material being linked, the immediate question of an implied licence arises. The implied-licence notion is based on the idea that, when uploading copyrighted material on the Internet, a carefully operating rightholder can be expected to be familiar with the special characteristics and conduct codes of the Internet. ${ }^{24}$ In the context of linking, a rightholder who delivers material via Internet presumably agrees to the material subsequently being linked. While an implied licence is not explicitly mentioned by the CJEU in Svensson, the ratio behind the case is closely related to the formulation behind the implied licence construction, since the CJEU seems to have adopted an interpretation that places responsibility on rightholders to clearly control access to copyrighted works. ${ }^{25}$ The reason why the CJEU has not directly referred to an implied licence might be that copyright contract law is not harmonised. The legal framework for assignments and waivers has been left to national legislative discretion since these legal acts depend on national law. ${ }^{26}$ The notion of an implied licence goes hand in hand with the doctrine of exhaustion, a doctrine originally based on the idea of an implied licence. ${ }^{27}$ Moreover, in some jurisdictions the idea that a buyer can use a product in any way they choose

\footnotetext{
${ }^{23}$ Jütte notes that although the CJEU did not address the freedom of expression dimension in Svensson, freedom of expression is nevertheless a crucial part of the case. Jütte (n 6), 18. A similar approach can also be seen in the ruling TV Broadcasting Ltd ym. v. TVCatchup Ltd, C-607/11, where the CJEU stated that when communication to the public is to be considered, the profit-making nature of the acts assessed or competitive relationships between the parties are irrelevant.

${ }^{24}$ Eg, J. Ungern-Sternborg, 'Schlichte einseitig Einwilligung und treuwidrig widersprüchliches Verhalten des Urheberberechtigten bei Internetnuzungen' 3-4 (2009) Gewerblicher Rechtsschutz und Urheberrecht 369, 370.

${ }^{25}$ Similarly S Karapapa, Stravroula 'The requirement for a "new public" in EU copyright law', 42 (2017) ELR 63,74 .

${ }^{26}$ Similarly, Geiger, Christopher and Schönherr, Franceska, 'The Information Society Directive, article 5'. In Stamatoudi, Irini and Torremans, Paul (eds) EU Copyright Law. A Commentary. (Edward Elgar Publishing 2014), 458-459. However, in general, the need for the EU to harmonise on copyright contracts has been discussed. See, eg, A. Strowel, 'Towards a European Copyright Law: Four Issues to Consider'. In Stamatoudi et al (n 26) $1137-$ 1138.

${ }^{27}$ See, eg, A. Kur, 'Completely Exhausted or Just Relaxed? Some Thoughts on the CJEU's "new exhaustion principle in Internet Linking Cases', with references therein. In Karnell et al (n 14) 443, 443.
} 
after purchase is directly based on the concept of an implied licence. ${ }^{28}$ The approach adopted by the CJEU is therefore inevitably close to construction of exhaustion, and the CJEU's decisions have been asserted as establishing de facto exhaustion of the right of making available to the public, while exhaustion should concern only the right of distribution. ${ }^{29}$

Naturally, the implied licence type of ratio is not applicable when illegal material is linked. Awareness of material being illegal is a natural doctrinal basis for liability in those cases. ${ }^{30} \mathrm{In}$ addition, profit-motivated activity can be considered as a circumstance creating a presumption of such knowledge, since such an actor can be considered as having a duty to act with an extra standard of care. Consequently, the division between these two lines of cases might undermine the diversity of interests in linking to material that is available with the author's consent. While a positive new element in GS Media and Filmspeler was that the economic interests were indirectly taken into consideration in the assessment of linking, it is hard to see why the relevance of assessing the commercial nature of linking should be limited to situations of linking to illegal material. ${ }^{31}$

Furthermore, a fresh look could be taken into the concept of 'communication to the public' by adopting a doctrine where the focus is more on weighing and balancing legitimate interests rather than on single-lensed functional aspects. It would be feasible for the CJEU to construct several lines of interpretation instead of two, based on a more comprehensive analysis of economic and freedom-of-speech-related interests.

\footnotetext{
${ }^{28}$ Eg, the House of Lords decision in United Wire Limited v Screen Repair Services (Scotland) 20.7.2000.

${ }^{29}$ It is explicitly stated in art 3 (3) of the Infosoc directive that a right to communication to the public shall not be exhausted by any act of communication to the public or making available to the public. As to this problematic see, eg, Mezei (n 3) 788-789. Kur takes a deeper perspective by stating that exhaustion as a technical legal term should not be assessed but instead a conflict between exclusive rights and fundamental freedoms. Therefore, a prerequisite is that the specific subject-matter of a right cannot be disproportionally affected. Kur (n 27) 452.

${ }^{30}$ However, the issue is complex since general liability issues are not harmonized in the EU. In principle, the alternative would have been to conclude that setting a link was unlawful, but due to the absence of negligence or required intention no liability arose. But this would have indicated a clash with the Member States' liability standards, typically setting strict liability for direct copyright infringements. Savola, Pekka 'EU Copyright Liability for Internet Linking' 8 (2017) JIPITEC, 139, 143.

${ }^{31}$ Mezei states that even though the line between commercial and private linking might be obscure and they might also involve similar consequences, nevertheless policy-related reasons might exist to distinguish between commercial and private linking. Mezei (n 3) 792. Kur, in her 'specific subject-matter approach' states that framing is not necessarily compatible with the principle of proportionality. However, she stresses that the mere fact that linking might reduce a rightholder's profits or that business models might be based on linking, does not amount to sufficient reasons to consider linking as covered by copyright. Kur (n 27) 458. Also the report by the Association Littéraire et Artistique Internationale, 'ALAI Report and Opinion on a Berne-compatible reconciliation of hyperlinking and the communication to the public right on the Internet' is based on the distinct legal status granted to cases of hyperlinking, and, on the other hand, to cases of deep-linking and framing. See http://www.alai.org/en/assets/files/resolutions/201503-hyperlinking-report-and-opinion-2.pdf
} 


\section{A possible solution...?}

In the context of assessing the feasibility of the concept of reproduction, I have proposed that in an imaginary world where international conventions would not create obstacles for revising the area of copyright exclusivity instead of reproduction, more attention should be paid to whether utilization of a copyrighted work affects, or is liable to affect, the legitimate interests of the rightholder, or alternatively, whether utilization follows honest practice in the particular sector of creative industry. ${ }^{32}$ Again, in the context of linking and communication to the public, the feasibility of similar kinds of general balancing mechanisms could be assessed, while no major obstacles should exist for creating lines of interpretation taking account of such general objectives.

Therefore, one solution might be to build lines of interpretation to differentiate various situations in the context of linking of legal material. One possibility here is to try to draw a distinction between loyal and disloyal purposes. As part of this assessment, a distinction might be needed between whether linking is commercial or without the intention to gain an economic advantage. Additionally, in the case of commercial linking, an important aspect is whether a service utilizing linking is based completely on systematic linking or whether linking is occasional in nature. Finally, another aspect that should be paid more attention to is whether linked material in commercial services is selected mainly by acts of the service provider or by acts of the user instead. This criterion might be important in drawing the distinction between genuine search services and services using linking techniques as tools for de facto distributing the works of others. In the latter cases, links are not genuinely used only in order to imply the location of certain material on the web. However, these criteria should only serve as guidance in the overall assessment of loyalty, which should always be connected to the development of the Internet and its business models. ${ }^{33}$

\footnotetext{
${ }^{32}$ See Pihlajarinne (n 15) 953-976.

${ }^{33}$ Adoption of this kind of legislation was, some years ago and before the CJEU's preliminary rulings, under active consideration in Finland. The Finnish Copyright Commission, chaired by professor Niklas Bruun from the University of Helsinki, published its final report 'Report of the Copyright Commission; Solutions to challenges of the digital age, Reports of the Ministry of Education and Culture, Finland 2012:2' on 26 January 2012 (available with English abstract

in http://www.minedu.fi/OPM/Julkaisut/2012/Tekijanoikeustoimikunnan_mietinto.html?lang=en). One of the several themes discussed in the report was commercial linking. The Copyright Committee decided to commission a study on commercial linking from the author of this article. The study assessed the feasibility of the various possibilities of setting rules concerning commercial linking. As a conclusion, the possibility considered the most promising was to adopt the kind of presumption rule - as discussed in this article - concerning an implied licence for linking. In addition, eg, using collective licence arrangements could be considered especially for news
} 
VI. ...but how about the future?

Linking itself as well as the interests behind it are under constant development. One remarkable factor is automatization and AI (by which is usually meant machine learning, where a machine teaches itself) in content production, which is already being used in editorial processes of news articles. ${ }^{34}$ This will undoubtedly have an impact on the issue of news aggregation, for instance. It is clear that many news items created with the assistance of AI are original enough to be copyrighted works. ${ }^{35}$ However, the crucial question is: who should hold the copyright for news created by AI, or indeed should anybody? Many parties are involved in the process: the programmer(s) and journalists who set guidelines on issues that are important in each topic (for instance, when writing an article on elections by utilizing automation, the success of political parties is more interesting than that of individual candidates) and rules on what kind of expressions can be used. The role of the AI user, such as a journalist, might be creative to some extent. Additionally, in developed AI systems, a distance might exist between the engineering of AI and work created by AI. ${ }^{36}$ While some analogies might be found from rules on copyright to apply to computer-generated works ${ }^{37}$, this alone is not sufficient since they do not take account of the special characteristics of more advanced and sophisticated AI in the future. ${ }^{38} \mathrm{It}$

aggregation services. After discussion of the options, the Copyright Commission decided not to propose any linking-related revisions to Finnish copyright law in the current situation. The Commission stated, however, that the study would give guidance to courts for assessment of linking-related copyright cases. In this assessment, a crucial factor should be - instead of linking techniques - the impact of linking on the legitimate interests of rightholders' and users' possibilities to gain valuable content in electronic form. These conclusions in the report have impacted assessment of linking cases in Finland by the Finnish Copyright Council (Copyright Council Decisions 2013:22 and 2014:14). The copyright Council is an organ appointed by the Finnish Government for, eg, issuing statements on the application of the Copyright Act in individual cases. It could be described as a softlaw type of dispute resolution mechanism, because its statements do not have binding effect but rather they have the nature of recommendations. Notwithstanding, they have great practical relevance as the number of court decisions in the copyright area is very limited.

${ }^{34}$ The reasons behind increasing interest in using automation in journalistic work are financial difficulties faced by news publishers combined with increased input in terms of news - since previously non-public data is to an increasing degree published openly in digital format - and demands for localization and personalization of news. See L. Leppänen, M. Munezero, S. Sirén-Heikel, M. GranrothWilding, and H. Toivonen 'Finding and Expressing News From Structured Data'. In Proceedings of AcademicMindtrek'17, Tampere, Finland, September 20-21, 2017, 1, 1. Available at https://www.cs.helsinki.fi/u/ljleppan/pub/leppanen2017finding.pdf.

${ }^{35}$ It is evident that, by utilizing AI, works can even be created that could be characterised as a piece of art, including literary art such as poetry. See, eg, J. Dickenson - A. Morgan and B. Clark 'Creative Machines: ownership of Copyright in content created by artificial intelligence applications', 39(8) 2017 EIPR 457, 457.

${ }^{36}$ Similarly Dickensen et al (n 35) 458.

${ }^{37}$ For instance, the UK copyright Act (CDPA) $9.3 \S$ stipulates that in the case of a literary, dramatic, musical or artistic work which is computer-generated, the author shall be taken to be the person by whom the arrangements necessary for the creation of the work are undertaken. In the case of algorithms, this might indicate that a copyright owner would be the one who created them, that is to say, a software engineer. However, the provision dates back to the time when the problems of AI had not yet arisen, while the provision might not be directly applicable to works created by AI. See Dickenson et al (n 35) 458.

38 On machine learning, see M. Hildebrandt 'Smart Technologies and the End(s) of Law'. Edward Elgar Publishing 2016, 35-36. 
is also possible that no human needs an incentive in these situations. Another option is that in copyright assessment in the era of AI the role of investment will attract substantially more attention than today.

However, it is evident that utilization of AI has the potential to revolutionize the ecosystem of incentives behind news production. If the investment needed for creative work by humans is essentially reduced on the part of news producers, if there is a tendency to consider programmers as authors instead of journalists, or if there is no copyright holder since nobody needs a utilitarian-sense incentive, then the question of linking might need careful reassessment. This is a relevant issue not only when considering news aggregation but also in terms of linking any material created by AI. Naturally, the guidelines established by the CJEU should be open for rapid change if needed to reflect changes in society or business logic.

\section{Conclusions}

From the perspective of legal fragmentation and overprotection, the DSM proposal on related rights for press publishers follows an unfortunate path in EU copyright. Continuous expansion of the area of exclusivity, especially creation of new related rights due to political pressure, is one problem. Moreover, this has been done by adopting new directives and narrow provisions, instead of amending existing ones and trying to create more flexible and principle-oriented rules. In order to avoid complicating EU copyright, problems that emerge should primarily be resolved whenever possible via CJEU case law instead of new directives. In areas with continuous impact of emerging technologies, problem-solving via CJEU case law could provide a mechanism equipped with the adaptability to respond when technical developments cause shifts in the economic or cultural basis of evaluation.

In considering linking on the one hand and the DSM directive proposal on the other, it is possible that instead of adopting a related-rights approach based on an overprotective attitude, some issues of news aggregation could have been solved by fine-tuning the case law on linking. Of course, it is equally possible that even in the case of such a solution, pressure for related rights would still have arisen.

The answer to the question contained in the topic of this Chapter could be the following: yes, it is as such possible to solve the problem of linking and copyright by functional-technical concepts - but not solely by those concepts. One solution is for the CJEU to build more lines of interpretation, based on enriched argumentation concerning legitimate interests and recognition of the diversity of linking situations, possibly by utilization of new auxiliary 
concepts. Of course, this would not serve those who favour simplistic solutions. However, flexibility and the possibility to re-evaluate assessment of legitimate interests and possible auxiliary concepts due to technical developments would be needed since development of AI and deep learning might fundamentally change the basis of how linking should be evaluated. The same concerns related rights, for instance - but the fundamental difference is that, once created, a related right is extremely difficult to revisit. 